\title{
Pedras que rugem: notícias sobre sete povos das missões
}

Luiz Cláudio Bittencourt*

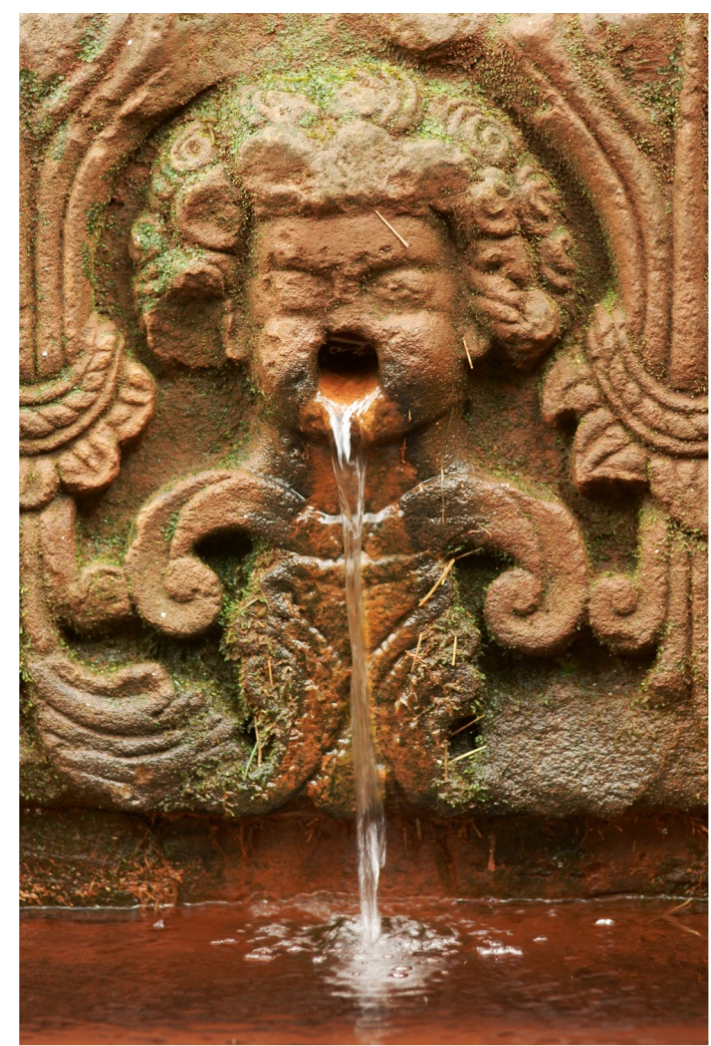

FIGURA 01 - Ampliação de querubim nascente próxima a São Miguel. Fotografia de Paulo Canguçu Fraga Burgo.

Caminhar pelas ruínas dos sete povos missioneiros do Brasil é tarefa inquietante: provoca angústia melancólica e simultâneos desejos de juntar os fragmentos do território escolhido pelos jesuítas para a utopia civilizatória da selva e do selvagem no sertão que fora paraguaio.

O sonho edênico ao lado do gentio catequizado é suplantado pelos interesses laicos do saque espanhol e lusitano de todas as riquezas possíveis. Entre elas, a mais significativa, é claro, a montanha de prata do Potosi, mas havia também a própria terra e seus moradores, únicos capazes de delimitar fronteiras de posses.

A tragédia do resultado hoje observado revela, no primeiro momento, o estranhamento do mundo colonial secular interessado na extração máxima das riquezas possíveis canalizadas em direção à metrópole e à vida privada do colonizador. Se os jesuítas desejavam almas em troca da civilização papal, o colonizador local ou metropolitano deseja apenas corpos e terras. 
O que aconteceu durante poucos séculos para formação desta paisagem desolada em que pedras lavradas em geometrias regulares, estranhas ao ambiente, enfrentam sozinhas o tempo, os homens e a natureza? Restos de colunas, vergas, ombreiras, cunhais... quem sabe? É difícil identificar em rápidas visadas os objetos soltos no cenário apresentado, desenhado em arranjos arqueológicos ou aleatórios. Permanece o efeito ruínas, restos fortes e pesados, remetidos ao passado impreciso, de difícil compreensão e identificação no arranjo geral.

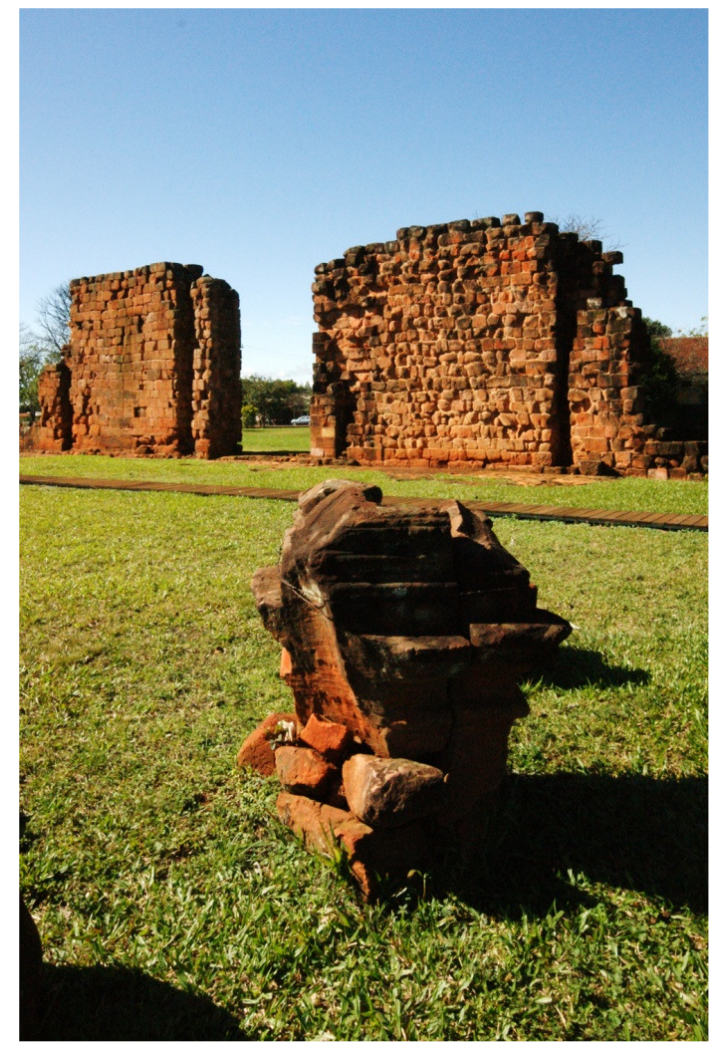

FIGURA 02 - Pedra da Ruína de São Nicolau revela exímia qualidade de trabalho sem caracterizar de forma precisa sua utilização. Fotografia de Paulo Canguçu Fraga Burgo.

Algumas paredes resistem aqui e ali, sem ordem ou razão. Pedras de várias origens assentadas em aparelhos de cantaria ou rejuntes de argamassas de barro ou de pedras pequenas. Lavadas pelo tempo resistem pela dureza e peso próprios, comprimindo-se ao chão enfrentam a vontade dos locais de limpar tudo em benefício do novo, como o Moderno, quando necessitava apagar para existir.

Não há memórias vivas possíveis entre os moradores de passado tão distante e tão etéreo, tudo é estranhamento, do cenário de objetos destroçados. Resta apenas a solidez e o peso das pedras, como leões magros fora do seu ambiente a rugirem de banzo em jaulas estreitas, são fantasmas, pálidas presenças de dignidades e imponências perdidas. 
Excetuada a pequena intervenção de Lúcio Costa em São Miguel (1), os restos dos sete povos revelam evidente falta de afetividade no sentido preciso apontado por Camillo Boito (2). Daí, talvez, a dificuldade de projetos de restauro que animem e recoloquem para a vida contemporânea o sentido perdido das partes desses colossos incrustados ao chão, sobras dos saques decorrentes das condições específicas do modelo de colonização ibérico e do modelo de urbanização da cidade contemporânea.

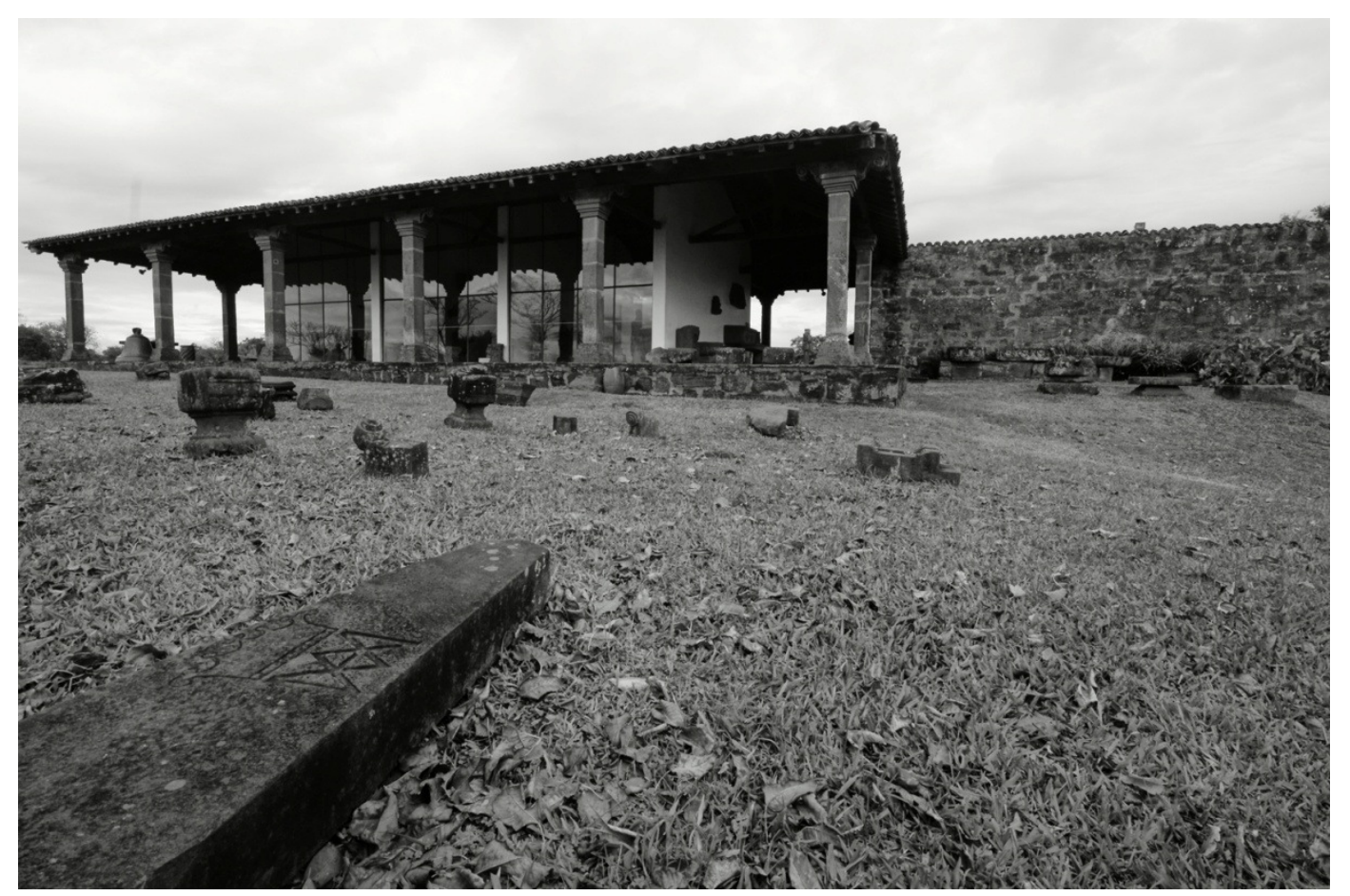

FIGURA 03 - Vista da intervenção de Lucio Costa em São Miguel. Fotografia de Paulo Canguçu Fraga Burgo.

\section{A dimensão urbana}

As missões revelam também novas escalas e complexidades adquiridas pelos bens tombados, em que as cidades surgem como ambiente hostil ou solidário, dependente de ações de salvaguardas ou de valorização dos acervos e monumentos. Nesse ponto o papel do Estado e de interação das comunidades vizinhas ainda pode ajudar.

As reduções eram em sua origem núcleos de aldeamentos sem pretensão de chegar à cidade necessariamente, pois quando atingiam certo limite de moradores uma 
nova redução era iniciada com os excedentes; a racionalidade geométrica está aliada à racionalidade de ordem social, que estabelece limites precisos à vida "urbana" e seu crescimento ao lado da estrutura espacial e seu desenho. Neste espaço e neste modo de vida marcado pela simplicidade funcional e geométrica, quem define tudo são os jesuítas e o projeto de catequese, sobrando pouco para o aleatório ou discórdia. Junto com o desenho urbanístico e arquitetônico vem também o planejamento social, moral, religioso e militar, cujo objetivo mais amplo é o controle do território na sua dimensão local e regional.

A discrepância entre este modelo de urbanização e os modelos ibéricos evidenciará o desaparecimento de um e a imposição do outro em momentos diferentes. Hoje vemos a solução vencedora articulada à formula tradicional que levou à constituição da cidade contemporânea. É a cidade fragmentada de base geométrica confusa e espaços organizados em função dos negócios imobiliários.

Este contexto comprime e ignora as ruínas como nos centro históricos das cidades industriais, onde os parques ferroviários e a arquitetura são cada vez mais apertados pela valorização imobiliária e as novas funções da cidade.

Os sítios, isolados ou em conjuntos, revelam com facilidade estas ponderações. De início, como a Roma medieval, esvaziada de moradores e das funções dos edifícios da Urbis, perdem também sua utilidade. A arquitetura é saqueada para construção da nova cidade; novo desenho urbano e outros edifícios são instalados sobre destroços e com os destroços. Nos povos onde surgiram cidades isto é evidente.

Em São Borja, cidade de 62.000 habitantes (3), nada resta; em São Luis Gonzaga, com 35.000 habitantes, também. Santo Ângelo, com 74.000 habitantes; é caso curioso: como nas outras duas, o traçado da cidade engoliu o sítio original onde estava implantada a última redução dos sete povos, "Santo Ângelo Custódio".

Hoje encontramos sobre o local das ruínas da igreja jesuítica original a construção do arquiteto austríaco Valentin Von Adamovich, que tem pretensão de reproduzir o projeto original das ruínas da igreja do sítio tombado da redução de São Miguel. É 
obra estranha no centro da cidade, apresenta efeitos surreais, agravados pelos achados arqueológicos em sua volta e no jardim da praça frontal.

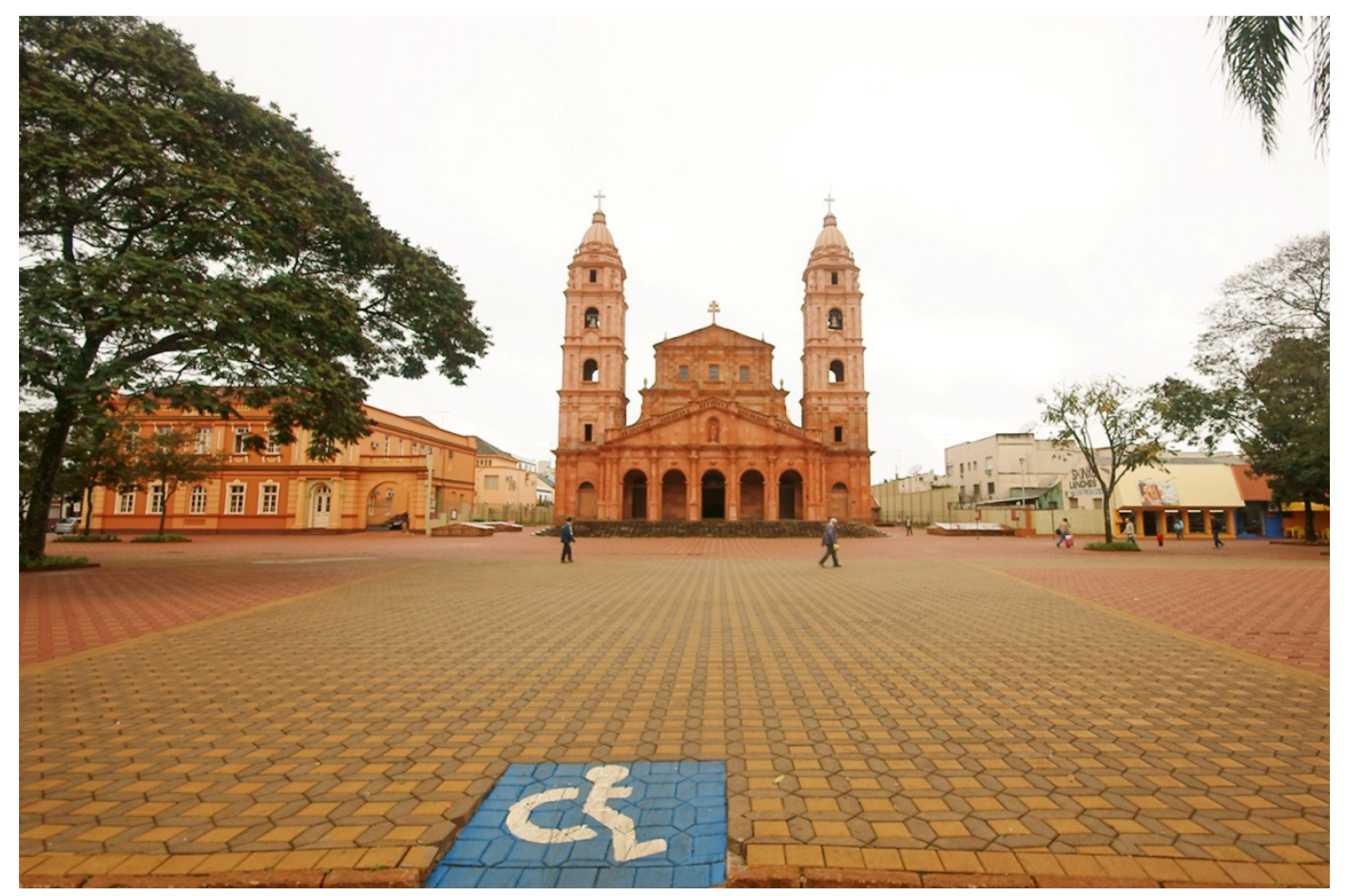

FIGURA 04 - Vista Igreja na Praça central de Santo Ângelo, projeto do arquiteto Valentin Von Adamovich. Fotografia de Paulo Canguçu Fraga Burgo.

A cor da pedra utilizada na fachada e a solução tipológica lembra São Miguel, mas o resultado final surge como simulacro do original, fora de contexto e de qualidade arquitetônica inferior à própria igreja anterior, substituta da original pertencente à redução, cujas características externas lembram as igrejas jesuíticas portuguesas do litoral brasileiro.

O resultado hoje apresentado é instigante, pois o conjunto da praça, orientado pelo desejo de edificar monumentos (4) através da réplica ou de invenções pueris, revela a destruição e o apagamento do que houvera. Com intervenções simplificadas ao lado de levantamentos arqueológicos, a população estabelece interações temporais entre sinais e significados desses objetos e a vida cotidiana dos moradores, em área da cidade que ainda é ponto de referência urbanística da vida citadina, com prefeitura, museu, escola, habitações e comércio em seu perímetro, perímetro que pertencera à praça central da redução. 


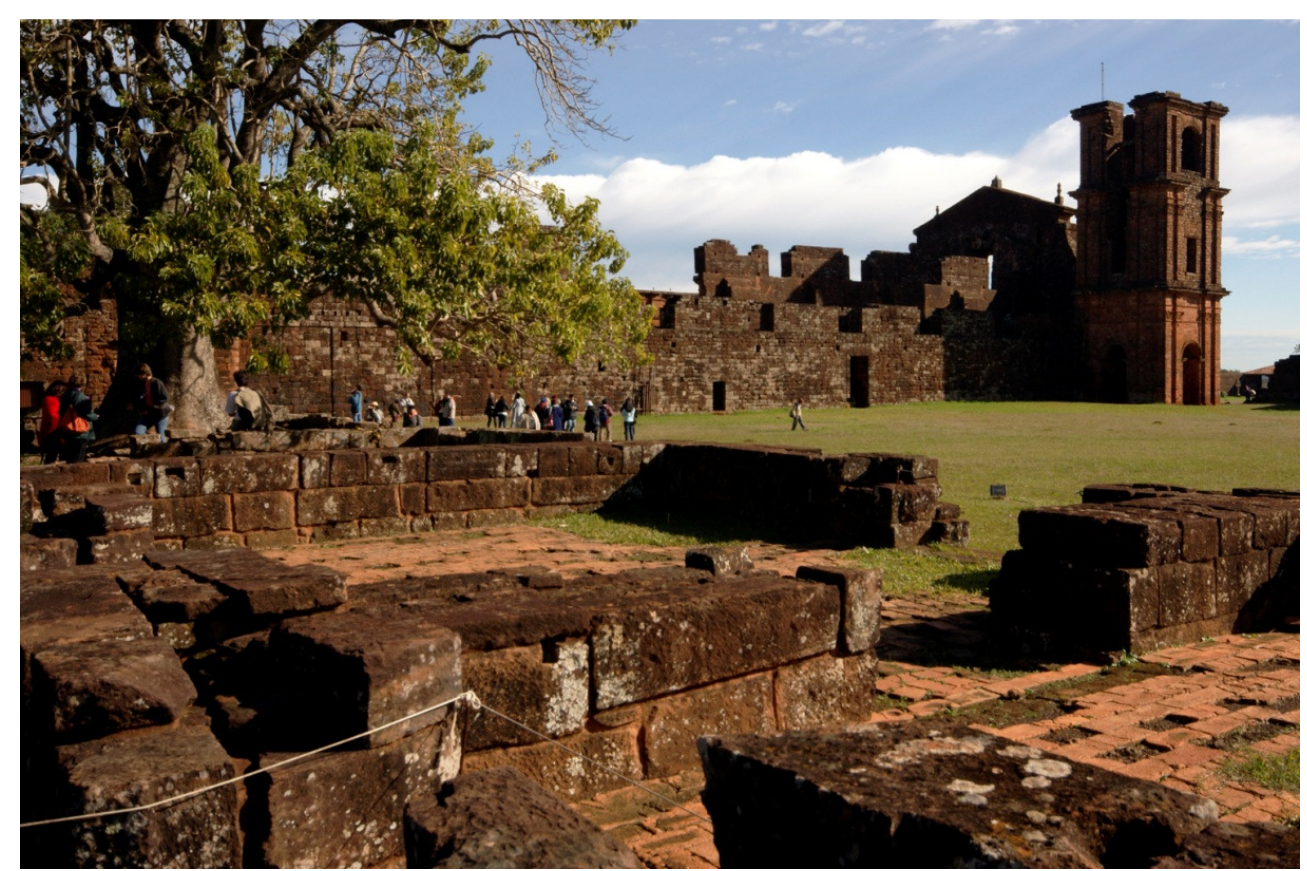

FIGURA 05 - Vista da nave e ruínas originais de São Miguel. Fotografia de Paulo Canguçu Fraga Burgo.

A dimensão urbana e urbanística - que eliminou os sítios de São Borja e São Luiz e consegue estabelecer vínculos em Santo Ângelo pela reconstrução, criação de monumentos e objetos arqueológicos de ruínas - possui outra conotação em São Miguel e São Nicolau. Nestas pequenas cidades a pressão da urbanização é menor e as relações com as ruínas que ainda existem são diferentes.

As ruínas de São Miguel estão marcadas pela presença do Instituto do Patrimônio Histórico e Artístico Nacional (IPHAN), que fez destas monumento de valor nacional e internacional, quer pela sofisticação da cantaria e textura do esqueleto da igreja ainda bem delineado, ou pela delicada e corajosa intervenção de Lúcio Costa com o projeto do Museu e da casa do Caseiro em um dos cantos da praça.

É um caso evidenciado pela existência do projeto novo, que amplia e valoriza as ruínas, exemplo em que as medidas de salvaguarda observáveis por especialistas não terminam com as pesquisas históricas, arqueológicas ou obras de contenção e consolidação do objeto. Há necessidade de intervenções que consigam relacionar o bem com o tempo vivido de forma ativa, de modo que a contemplação apareça como momento de diálogo entre o novo e o antigo, em linguagem de fácil compreensão ao leigo. 
É sem dúvida o principal sítio em termos de conservação e medidas protetoras, mas as constrições provocadas pelas formas de urbanização contemporâneas já estão presentes no seu perímetro, envolvendo a área pelo traçado das ruas dos novos loteamentos. Situação que talvez tenha obrigado o cercamento do conjunto com alambrados, afastando e hostilizando as pedras transformadas em patrimônio histórico nacional e internacional já há algum tempo. Assim o acervo surge como objetos estranhos, obscuros à compreensão do morador comum dedicado ao comércio local ou à vida rural. A população parece temer e admirar o cenário surreal de difícil articulação com o dia a dia dos seus vizinhos.

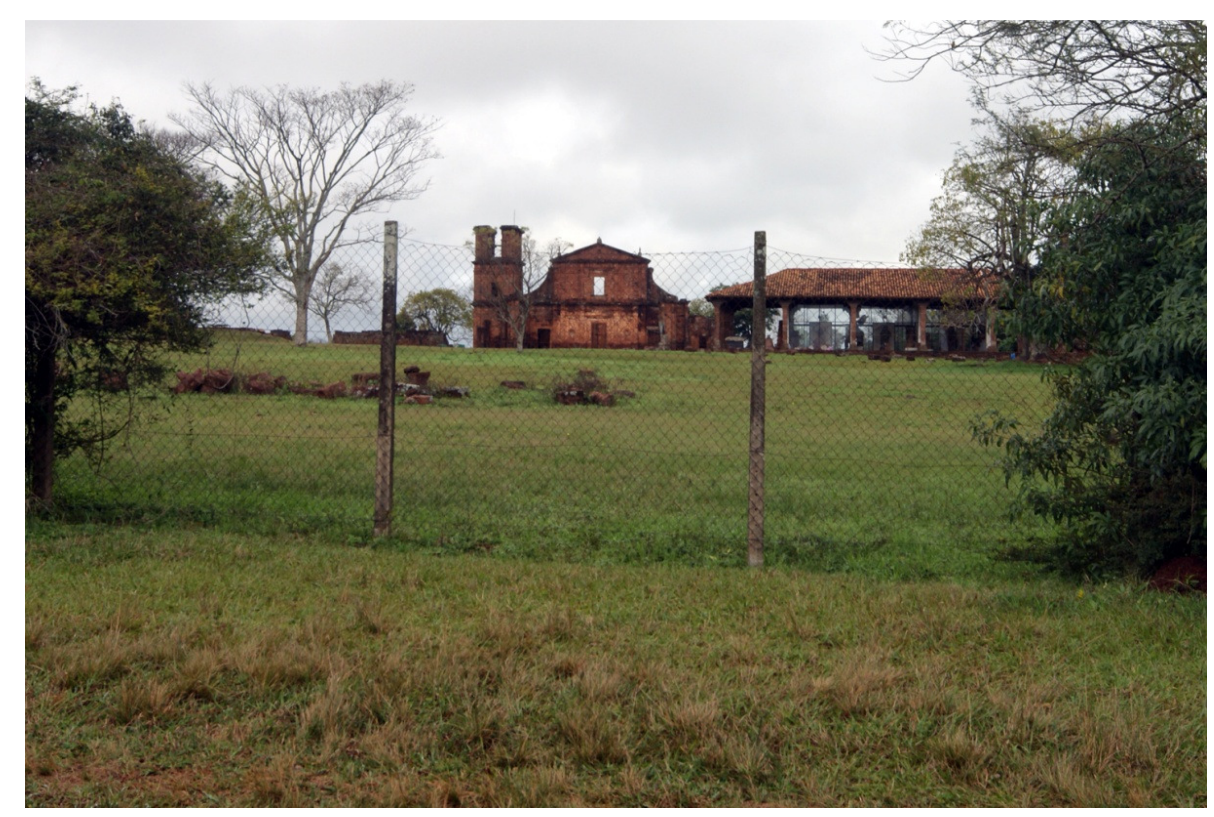

FIGURA 06 - Vista frontal do principal sítio arqueológico da Ruína de São Miguel evidenciando o alambrado de divisa entre as ruínas e a cidade que o cerca. Fotografia de Paulo Canguçu Fraga Burgo.

O turismo gerado absorvido pelas pousadas e hotéis sofisticados tangencia a cidade com valores distantes.

São Nicolau, embora da mesma proporção de São Miguel, apresenta características diferentes: as ruínas não possuem a mesma sofisticação da cantaria ou unidade da igreja de São Miguel, são paredes soltas aqui e ali, pedras esparsas, fundações, drenagens de águas pluviais. A cidade pilhou o que pôde para construir seus edifícios com aproveitamento das pedras existentes; é possível encontrar pedaços das ruínas em casas simples ou sofisticadas, como no interessante casarão do século 19 no limite do arruamento. 


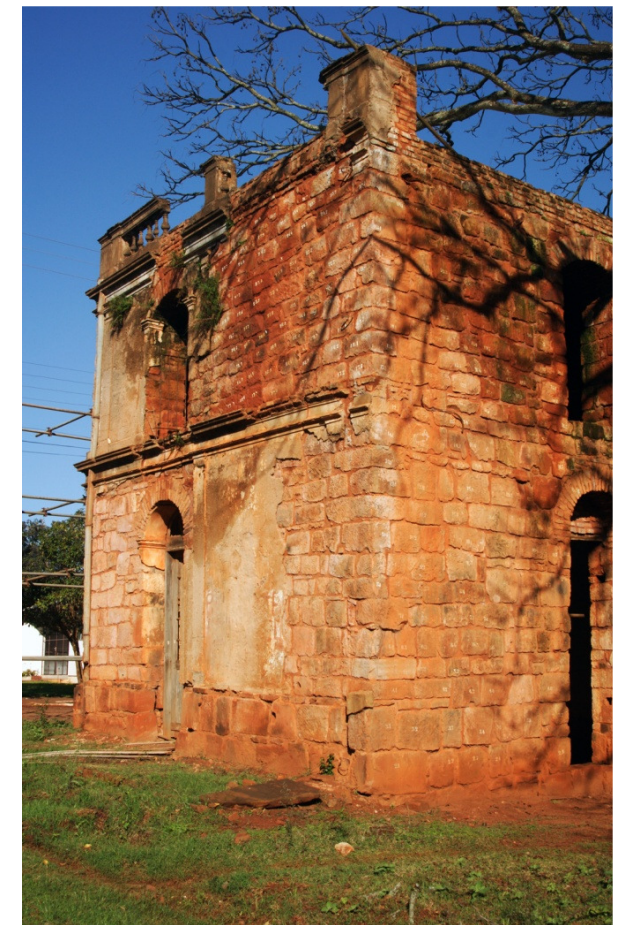

FIGURA 07 - Vista lateral do casarão construído com pedras extraídas das ruínas de São Nicolau. Fotografia de Paulo Canguçu Fraga Burgo.

Ainda assim, as ruínas parecem estabelecer relações positivas do ponto de vista da integração com o desenho urbano e a população local, talvez pelo fato do arruamento abraçar o perímetro do que restou, ou pela presença de uma escola ao lado, ou pelas casas de moradia e igreja; talvez porque a comunidade estabeleça outras relações com o turismo que chega recentemente, sem grandes projetos de hotelaria, dependendo de pequenas pousadas ou da hospedagem de particulares.

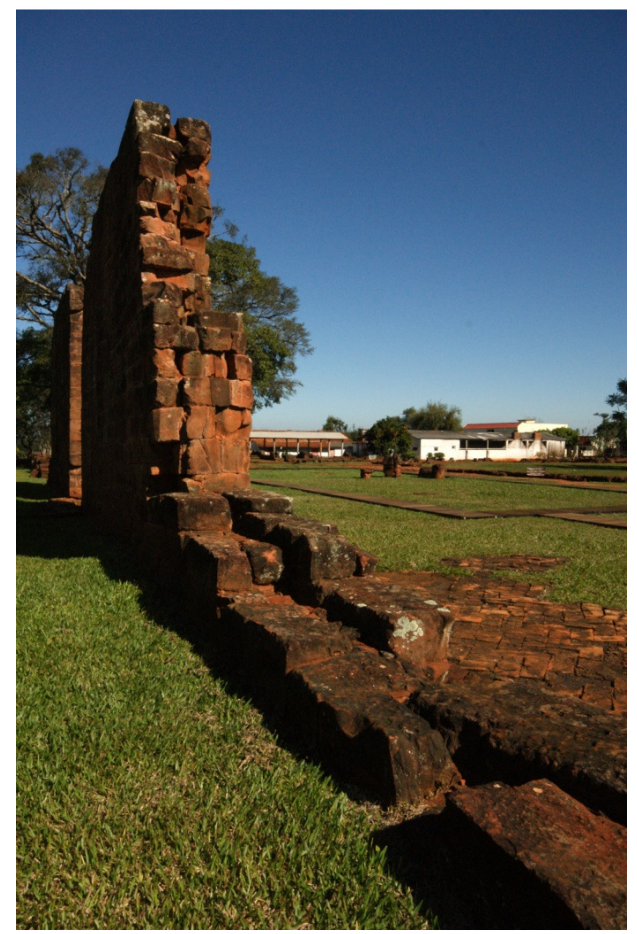

FIGURA 08 - Vista de São Nicolau demonstra a proximidade entre os edifícios locais e a ausência de barreiras entre as ruínas e a cidade. 
Do ponto de vista, as ruínas ficaram sobre o espaço que possui características de praça: elas não estão separadas por cercas ou alambrados, são permeáveis aos transeuntes, que convivem com naturalidade e aparente compreensão utilitária, aproximando seu significado histórico para cidade e para o sentido de patrimônio histórico.

A permeabilidade espacial e funcional da condição de praça é ampliada pelo projeto de jardim inserido de maneira confusa e ingênua por entre as ruínas, colocando o observador em condição de integração com o passado estranho, sempre mal explicado e de valor institucional, reconhecido em diálogo formal com sabores estéticos do momento vivido, acolhendo no mesmo cenário signos diferentes como o popular e o sofisticado.

Em São Nicolau, onde a pequena cidade se faz presente, o meio urbano é tão hostil quanto nas demais, mas na outra mão o acolhimento da idéia do objeto estranho, arruinado em parte pela história e pelas necessidades da própria cidade, parece menos dolorido e de assimilação mais dócil pela comunidade de moradores.

São João e São Lourenço estão na outra ponta do quadro apresentado. Aqui a paisagem é rural, a população é pouca e diluída entre sítios, vendas ou capelas. Não existe aperto do traçado de ruas ou da vida urbana; interesses imobiliários ocorrem em outra escala que não é a do lote ou do edifício urbano. Mas o cenário de desolação se repete. Os ventos arrasadores das guerras, dos saques e do tempo estão presentes, na forma de pedras brotando do chão em empenas de edifícios virtuais.

Nestes sítios preservados da urbanização, o arqueólogo parece encontrar terreno rico para organizar escavações sistemáticas sem camadas de história recente: é a condição do monumento isolado, laboratório perfeito. Mas o isolamento não costuma favorecer o patrimônio histórico ou projetos de restauro.

Nos dois casos, o visitante é recebido em pequeno portal da entrada. É intervenção arquitetônica simples, com pequena infraestrutura de sanitários, suporte do vigia e 
sala para pequenos achados nas escavações e rápido relato primário sobre a história.

Ao entrar no sítio original, preservado por cercas de gado, o visitante encontra o mesmo cenário de pedras lavradas distribuídas sobre gramado estranho à paisagem existente e ao chão original de terra batida. Aos poucos, o tapete verde conduz a interessantes passarelas em deques de madeira que separam o observador da condição aleatória. Aparentemente, procura-se tratar os espaços como museu ao ar livre, com placas informativas a cada deslocamento. Apesar de não privilegiar o olhar arquitetônico, a iniciativa valoriza o bem tombado pelo tratamento distanciado, evidenciando o precioso, conduzindo aos poucos o visitante a delinear monumentos históricos de escala nacional.

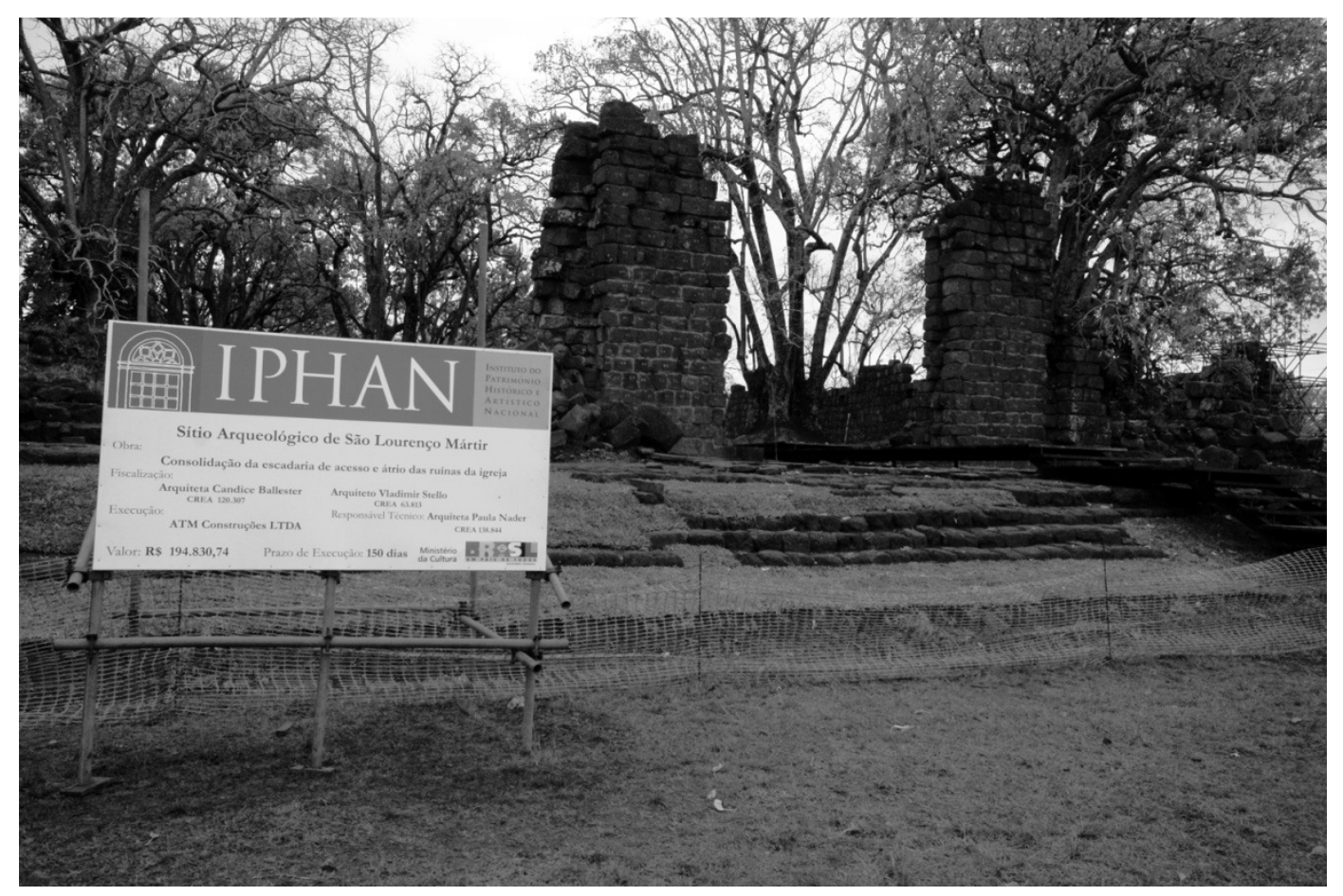

FIGURA 09 - Vista da ruína de São Lourenço protegida por cerca construída pelo IPHAN para contenção de turistas e da pastagem. Fotografia de Paulo Canguçu Fraga Burgo.

Esta relação entre o objeto transformado em jóia intocável de característica monumental sublima a percepção do olhar do visitante eventual, mas está longe da realidade local, que parece mais interessada na utilização dos cemitérios sobreviventes, que continuaram com seu uso ao longo dos séculos, evidenciando a importância do campo santo na aglutinação e constituição dos bairros rurais, aldeias, vilas e cidades brasileiras. 


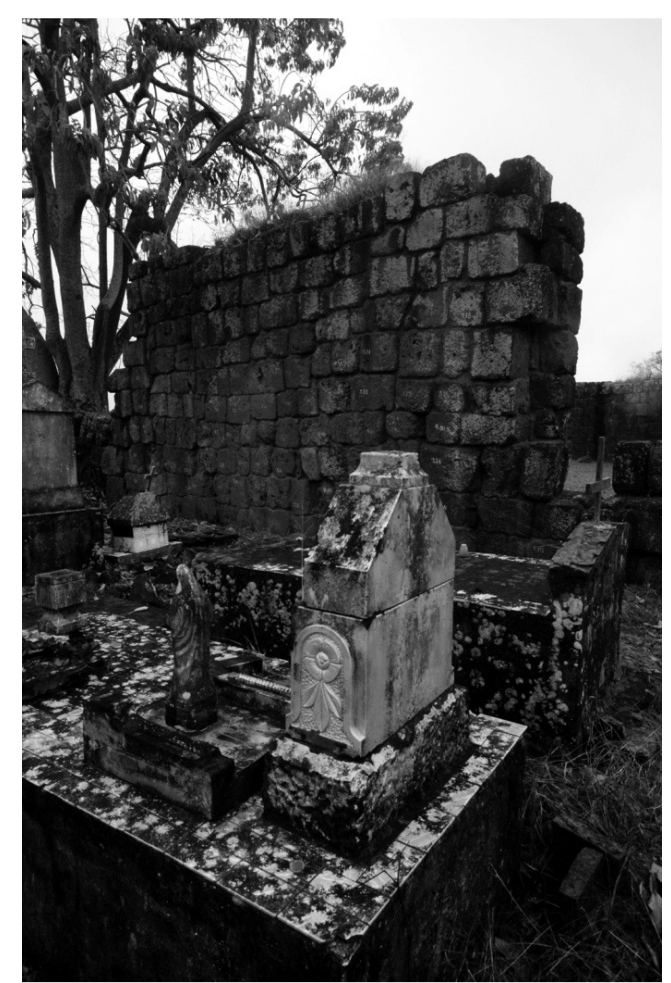

FIGURA 10 - Ruína de São João vista do cemitério demonstrando sua utilização recente. Fotografia de Paulo Canguçu Fraga Burgo.

Em quase todos os casos, fica evidente a dificuldade de proteger as ruínas da ação do tempo e da natureza juntos. Cerca de trezentos anos nos separam do momento em que os jesuítas cruzam o Rio Uruguai para constituir a linha em direção nordeste de São Borja a Santo Ângelo, pontas dos sete povos. Não é pouco, para o tempo dos homens e da natureza; entre as construções e destruições pela posse e domínio da terra, as pedras lavradas são testemunhos da fúria humana aqui registrada, mas o que vemos hoje nos sítios de São Lourenço e São João é o domínio da natureza sobre a fábrica.

Retirados os eventos demarcados pelas intervenções arqueológicas, o cenário transformado em museu transpira abandono: raízes contorcidas coladas às pedras duramente lavradas, nuas de reboco, esmagam o resultado do trabalho que deveria ser revelado. É resultado que se situa na contramão da intenção de resgatar acervo que, pelo seu valor intrínseco, está transformado em patrimônio da humanidade (5).

\section{Restauro e patrimônio histórico}

Neste texto, procuramos noticiar a cada passo, de maneira específica, algumas características sobre o papel do projeto de restauro e dos aspectos das ações de gestão institucional do patrimônio histórico como ação de Estado nas medidas de 
salvaguarda de determinados bens tombados. Como no projeto de arquitetura e urbanismo e nas políticas públicas, toda generalização parece inadequada, suscitando erros que descolam o objeto do contexto delimitado pelo tempo, espaço e território.

Nestes casos, propostas devem seguir retóricas indutivas emanadas dos objetos tratados, sem prejuízo do repertório teórico temático que cada caso demanda (6) do ponto de vista estético, social e político.

Em relação às ruínas, procuramos sobretudo sua dimensão sublime de sugerir espaços em paisagens virtuais, às vezes melancólicas, mas instigantes à curiosidade do passado ainda presente (7). Deixá-las à deriva, ou consagrá-las às pesquisas historiográficas ou arqueológicas, parece pouco e não reverte o processo de apagamento tão evidente nos casos aqui apresentados.

A intervenção corajosa, contemporânea, didática, pode restabelecer interações eruditas e singelas que incomodam o observador leigo ou preparado, mas, sobretudo, parece criar possibilidades de convivências entre a sabedoria prosaica e o saber acadêmico, revivendo nos diálogos significados e valores latentes.

Afinal é difícil imaginar a Companhia de Jesus movimentando os recursos para instalar a civilização "cristã - guarani" no sertão latinoamericano, ao lado das águas mais cobiçadas do planeta (8), sem o domínio preciso do significado que este território possuía e possui. Investimentos que custaram o fim dos Jesuítas e do seu projeto naquele momento, que certamente não caminhava na mesma direção do projeto de colonização que desaguou no modelo esgotado da realidade contemporânea.

\section{Tratando de ruínas}

Sobre ruínas e projeto de restauro em arquitetura, exemplo instigante pode ser contrastado com as soluções encontradas até o momento nos sete povos: trata-se da "Casa Grande e Tulha" de autoria de Antonio da Costa Santos na cidade de Campinas. 
O velho edifício de taipa de pilão de cerca de duzentos anos de existência nasce como morada sertanista do "Pouso das Campinas Velhas", primeiro núcleo de aldeamento que deu origem à atual cidade de Campinas. Situado hoje no Bairro Proença, mantém o traçado da "Estrada dos Guaiases" dentro da gleba que restou da velha "Chácara do Paraíso" do século 19. (9).

Não há termos de comparação enquanto objetos históricos ou arqueológicos, mas vale destacar o método de projeto de restauro utilizado, em contraste ao encontrado nos sete povos.

Considerada a escala e a liberdade de ação de que o arquiteto dispôs pelo fato de ter adquirido os edifícios para sua moradia, permanece a imposição do projeto contemporâneo contrastando com o edifício típico da arquitetura bandeirista (10). Escolher o que remover e o que manter a partir de meticulosa prospecção passa pelo filtro definido pela postura do projeto inicial, com programa de uso ainda nebuloso, mas com visão estética clara que valoriza o antigo em sua museografia formal e técnica, possibilitando sobrevivência e conservação hoje.

A busca pela beleza através da escolha de técnicas e tecnologias contemporâneas que estabeleçam linguagens por contrastes evidencia o novo e o antigo pela visão do óbvio, mas com uma fina conexão de empatia viva em relação ao comportamento estático e dinâmico entre matérias resistentes à compressão e tração, ao mesmo tempo frágeis a fungos e oxidações que o tempo impõe.

O ambiente é útil no limite da integridade dos diálogos estabelecidos entre projetos diferentes no tempo e autoria. Um novo espaço surge desta convivência, não é mais o edifício defensivo do pouso com três empenas cegas e únicas aberturas para o velho terreiro, também não é um museu de costas para a cidade e o sistema viário do loteamento que o comprimiu. É um prisma de terra socada, perfurado de cabodás (11), rasgado pela contração da terra, pelas águas pluviais e pelo pragmatismo utilitário inconsequente que o descuido de antigos proprietários inflingiu.

De um lado a terra e a madeira lavrada, de outro concreto e aço, trabalhando juntos, mas separados por limites claros, consolidam e reestruturam o conjunto, ampliando 
sua vida útil do ponto de vista da estabilidade e das drenagens pluviais, ao mesmo tempo em que a crueza na utilização de cada matéria em estado bruto parece fragilizá-lo visualmente. Aproximando a ruína das novas intervenções, oferece sentido de vida e beleza precárias, pronto a se dissolver pelo tempo se não for acariciado pela vida pública e privada necessárias à alimentação dos monumentos (12).

O velho e o novo transformam-se em outra coisa, a mão do trabalho escravo associa-se com as máquinas que produzem o aço e o concreto da arquitetura moderna; juntos, transformam a velha ruína em objeto museológico em si que pode ser contemplado da rua ou do seu interior.

Não há intenção de que estes parágrafos apresentem estudo de caso para confronto ou contraposição generalizáveis; apresentamos possibilidades de ações cuidadosas no tratamento de ruínas arquitetônicas, em outro contexto. Não é o único caminho interessante; basta visitar os sítios italianos ou franceses, mas vale lembrar a constante em quase toda bibliografia sobre este tema: a leviandade pragmática e utilitária ao lado da indiferença e distanciamento que observamos nos sete povos é quase sempre mais agressiva para conservação e salvaguarda do patrimônio histórico que o tempo.

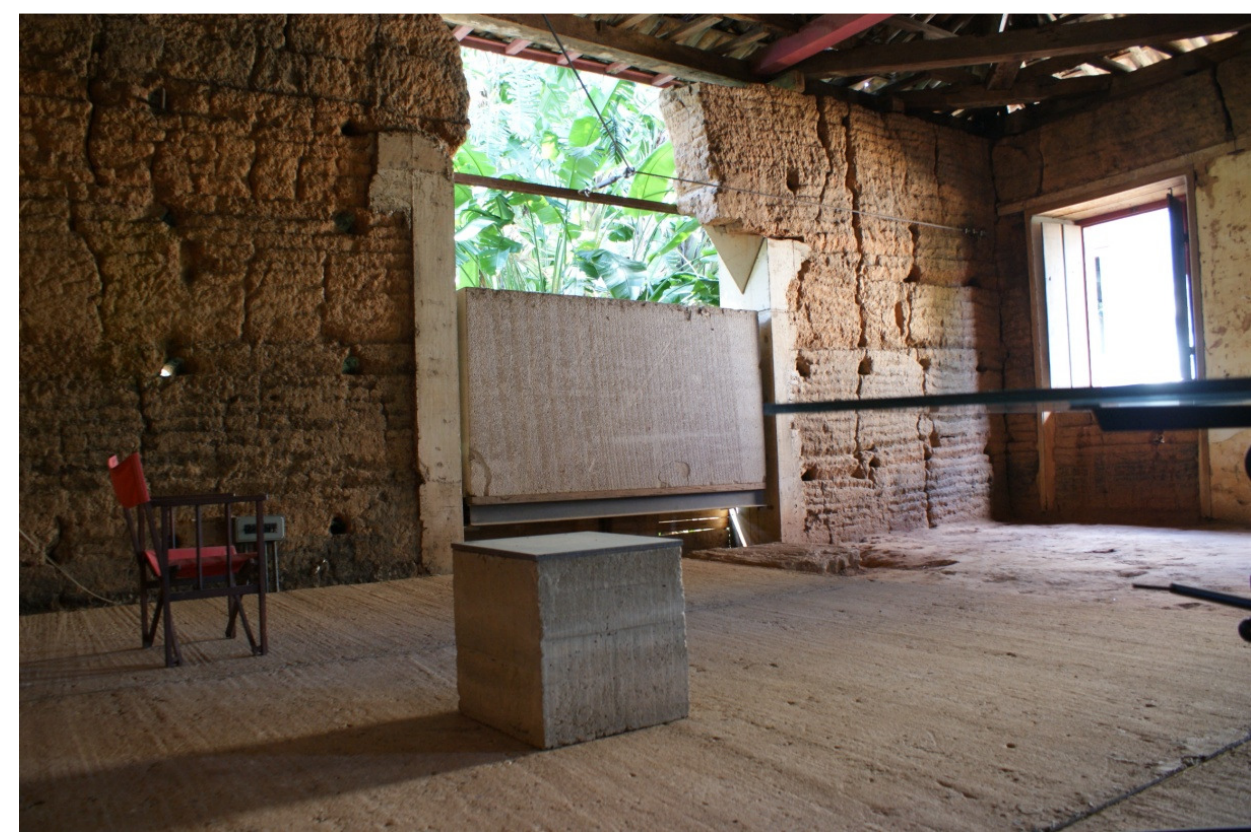

FIGURA 11 - Casa de taipa de pilão antigo "Pouso das Campinas Velhas", Campinas, SP. Fotografia de Paulo Canguçu Fraga Burgo. 
A reutilização pelos moradores do material removido das ruínas ou encontrados de forma dispersa aqui e ali sem que o usuário compreendesse o valor ou o significado utilitário perdido, como acontece na casa que virou museu em Santo Ângelo ou no casarão eclético abandonado na periferia de São Nicolau, parece caminho mais verdadeiro que o abandono pela indiferença ou reconstruções nostálgicas cenográficas, como o pequeno edifício ao lado do museu de São Nicolau, em frente à praça, onde se encontram as ruínas mais significativas desta redução.

Nestes velhos povos percebemos a dificuldade de projetar com ruínas: inventá-las onde não existem parece romper com sua profunda característica expressiva banalizando o fato histórico e corroendo os significados do monumento. Em São Nicolau existe uma bicicletaria de madeira que utiliza em uma das faces da construção o que restou de uma velha parede original da redução, inclusive com vãos de porta e janela. Curioso é que esta parede está no alinhamento do traçado da rua, oferecendo interessantes prospecções arqueológicas. Para o observador desavisado fica a confusão se esta parede é fruto de saque e reconstrução, além do desagrado diante das limitações estéticas decorrentes das adaptações precárias de um edifício pobre, mas fica evidente que é um lugar de muita atividade. É tão natural o convívio entre os usuários locais e a peça histórica, que ela passa quase despercebida.

Recriar espaços de arquitetura e urbanismo antigos diante de temas que envolvem patrimônio histórico, restauro e sítios arqueológicos não é tarefa fácil. Às vezes é possível encontrar um monumento aqui e ali, outras não; às vezes é possível sublimar o fato histórico e elevá-lo ao status de monumento histórico, local ou nacional, outras o artefato existe apenas em convívio discreto com seus usuários, diluído na paisagem interagida pelo cotidiano, como as antigas vilas medievais da Europa.

Em seu relatório de visita aos "Sete Povos", em dezembro de 1937, Lúcio Costa oferece - além do projeto do pequeno museu e da casa do zelador como possibilidade específica de intervenção em ruínas - sua visão de como seria possível restabelecer a reconstrução do imaginário do visitante decorrente da convivência cenográfica entre o monumento histórico e o novo sem minimizar a interação 
cotidiana com os locais. Duas soluções no mesmo projeto, hoje descaracterizado pela ausência de zelador, e transformação da sua morada em contínuo do museu.

O "museu" deve ser um simples abrigo para as peças [...]. Aliás, para que os visitantes, geralmente pouco ou mal informados "compreendam" melhor a significação das ruínas, sintam que já houve vida dentro delas e, se possível, também, "vejam", como o Sr. Augusto Meyer, "aquela porção de índios se juntando de manhãzinha na igreja,[...]". (LUCIO COSTA, 1999, p. 39).

O arquiteto moderno autor dos projetos deixa evidente: a sua intervenção deve ser pequena para não concorrer com o efeito de monumentalidade criado pelo piso árido e limpo da grande praça em relação ao eixo de visão da fachada da igreja - ao contrário, deve valorizar este efeito pelo contraste, artifício da arquitetura e do urbanismo conhecido desde a invenção da "cidade capital" como espaço nuclear do "moderno estado nacional" e do barroco. Linguagem que nunca escondeu dominar, trabalhando com maestria a velha fachada arruinada do barroco de São Miguel (13).

\section{Notas}

(1) COMAS (2007).

(2) O autor vincula critérios de restauração à atitude inicial de cultivar e desejar o bem com dignidade e respeito aos princípios constitutivos originais do objeto e valores estéticos de cada tempo e cada intervenção. BOITO (2008).

(3) Os dados quantitativos foram retirados do IBGE senso de 2000 atualizado para 2007-2008, arredondando as centenas para cima, http://www.ibge.gov.br.

(4) A idéia de monumento apresentada aqui pela segunda vez coaduna em parte com visão um tanto estática recentemente abordada (CHOAY, 2001), outros trabalhos enfocam o tema ligado a certa concepção de espaço (ARGAN, 1964 e1973) e a monumentalidade como efeito provocado por esta concepção de espaço, desde a formação do Moderno Estado Nacional e o surgimento da "Cidade Capital".

(5) Sabemos que apenas o sítio de São Miguel é reconhecido pelo UNESCO, mas não podemos esquecer as recomendações da Carta de Veneza que ressalta a importância do conjunto para reconhecimento do monumento isolado.

(6) Aplicação do raciocínio indutivo ou dedutivo decorre também de longa experiência sobre a cidade de Campinas nos anos oitenta e noventa envolvendo Grupo Febre Amarela, constituição do Conselho do Patrimônio Cultural de Campinas, Fundação da Cidade e Instituto CIVITAS, além dos projetos de restauro do DCE- 
UNICAMP e Casa Grande e Tulha do arquiteto Antonio da Costa Santos. Cf. COSTA SANTOS; BITTENCOURT, 1985 e 1998, COSTA SANTOS, 2002 e BITTERNCOURT, 2009.

(7) Cf. CARENA, 1984.

(8) Cf. ALMEIDA, 1999.

(9) Para análise detalhada do edifício e sua relação urbana e urbanística ver: COSTA SANTOS, 2002.

(10) Cf. SAIA, 1972.

(11) Orifício que fica nas paredes feitas de taipa de pilão, após serem retiradas as agulhas (peças cilíndricas de madeira).

(12) Cf. CHOAY, 2001.

(13) O caso mais conhecido é o eixo monumental de Brasília, conquistado não pela macrocefalia de edifícios agigantados, ao contrário, os edifícios são proporcionais à escala humana adequada ao corpo e ao domínio da visão. O sentido de monumentalidade de Brasília parece caminhar pelos espaços não edificados e pelos significados de cada edifício (ARGAN, 1964).

\section{Referências Bibliográficas}

ALMEIDA, André Ferrand. Os jesuítas matemáticos e os mapas da América Portuguesa (1720-1748). Oceanos, n. 40, p. $79-92,1999$.

ARGAN, Giulio Carlo. La Europa de las capitales. Geneve: Skira, 1964.

El concepto del espacio arquitectónico desde lo barroco a nuestros dias. Buenos Aires:

Nueva Visión, 1973.

Clássico anticlássico: o Renascimento de Brunelleschi a Brugel. São Paulo: Cia. das

Letras, 1999.

História da arte italiana. São Paulo: Cosac \& Naify, 2003. 3 v.

BITTERNCOURT, Luiz Cláudio. Riscando a cidade - Cartografia histórica e desenho urbano de Campinas. Campinas: Editora Arte Escrita; Centro de Memória Unicamp/Fapesp, 2009.

BOITO, Camillo. Os restauradores. Cotia, SP: Ateliê Editorial, 2008.

BRANDI, Cesare. Teoria da restauração. Cotia, SP: Ateliê Editorial, 2004.

CARENA, Carlos. Ruína/Restauro. In: Enciclopédia Einaudi. Porto: Imprensa Nacional/Casa da Moeda, 1985. 
CHOAY, Françoise. A alegoria do patrimônio. São Paulo: Unesp, 2001.

COLLINS, George R. Camillo Sitte y el nacimiento de urbanismo moderno. Barcelona: Gustavo Gili, 1980.

COMAS, Carlos Eduardo. (Org.). Lúcio Costa e as Missões: um museu em São Miguel. Porto Alegre: Propar/UFRGS/IPHAN, 2007.

COSTA SANTOS, Antonio. Campinas, das origens ao futuro: compra e venda de terra e água e um tombamento na primeira sesmaria da freguesia de Nossa Senhora da Conceição das Campinas do Mato Grosso de Jundiai (1732-1992). Campinas: Editora da Unicamp, 2002.

COSTA SANTOS, Antonio; BITTENCOURT, Luiz Cláudio. Campinas, circunscrição e gênese. In: SEMINÁRIO DE HISTÓRIA DA CIDADE E URBANISMO, 5., 1998, Campinas. Anais...Campinas: PUCC, 1998. CD-ROM.

Restauro do DCE-UNICAMP: tradição e ruptura síntese de arte e cultura brasileiras. São Paulo: Fundação Bienal São Paulo, 1985.

FRANKL, Paul. Principios fundamentales de la historia de la arquitectura: el desarrollo de la arquitectura europea, 1420-1900. Barcelona: Gustavo Gili, 1981.

GONÇALVES, Cristiane Souza. Restauração arquitetônica: a experiência do Sphan em São Paulo, 1937-1975. São Paulo: Annablume; Fapesp, 2007.

LE GOFF. Jaques. Por amor às cidades. São Paulo: Unesp, 1998.

LUCIO Costa: documentos de trabalho. Coordenação de José Pessôa. Rio de Janeiro: Iphan. 1999.

RUSKIN. John. As pedras de Veneza. São Paulo: Martins Fontes, 1992.

Las siete lámparas de la arquitectura. Buenos Aires: Sadian, 1955.

RYKWERT, Joseph. A sedução do lugar, história e o futuro da cidade. São Paulo: Martins Fontes, 2004.

SAIA, Luis. Morada paulista. São Paulo: Perspectiva, 1972.

VIOLLET-LE-DUC, Eugène Emmanuel. Restauração. Cotia, SP: Ateliê Editorial, 2006.

\section{Crédito}

* Doutor em Arquitetura e Urbanismo pela Universidade de São Paulo (2000), pós-doutor pelo Instituto de Geociências da UNICAMP (2007). É professor do Curso de Arquitetura, Urbanismo e Paisagismo da FAAC-UNESP-Bauru. Assessor da Fundação de Amparo à Pesquisa do Estado de São Paulo (FAPESP). Coordenador do Curso de Arquitetura e Urbanismo das Faculdades Integradas de Ourinhos. Coordenador do Instituto de Pesquisas CIVITAS.

e-mail: civitas-campinas@uol.com.br 